\title{
PREVALENCE OF OBESITY AMONG URBAN SCHOOL CHILDREN OF KOCHI
} CITY

Shiji K. Jacob ${ }^{1}$

\section{HOW TO CITE THIS ARTICLE:}

Shiji K. Jacob. "Prevalence of Obesity among Urban School Children of Kochi City" Journal of Evolution of Medical and Dental Sciences 2014; Vol. 3, Issue 08, February 24; Page: 1991-1996,

DOI: $10.14260 /$ jemds/2014/2092

ABSTRACT: OBJECTIVE: To study the prevalence of obesity and overweight among urban school children in Kochi. SETTING AND DESIGN: Secondary data analysis of a school-based cross sectional study of an urban school of Kochi. MATERIALS AND METHODS: A cross-sectional study was conducted in a private school in Kochi, India. A total of 1178 school children in the age group of 6-15 years were studied. Weight and height of each student was measured using standard measures and body mass index (BMI) was calculated. For children and teens, after BMI is calculated, the BMI number is plotted on the CDC BMI-for-age growth charts (for either girls or boys) to obtain a percentile ranking.Statistical analysis: Chi-square test. RESULTS: The prevalence of overweight ( $\geq 85$ th percentile) among children was $10.1 \%$ and prevalence of obesity ( $>95$ th percentile) was $5.6 \%$. Boys had the highest prevalence of overweight (11.5\%) and obesity (6.53\%). Male children from private schools and urban areas were at greater risk of being overweight and obese. CONCLUSIONS: Childhood obesity is a problem in boys and requires timely intervention for its control.

KEYWORDS: Obesity, body mass index, school children.

INTRODUCTION: Obesity is one of the most prevalent nutritional disease of children and adolescents in many developed and developing countries. ${ }^{1}$ The World Health Organization (WHO) has declared overweight as one of the top ten health risks in the world and one of the top five in developed nations. ${ }^{2}$ Existing WHO standards and data from 79 developing countries including a number of industrialized countries suggest that about 22 million children five years old are overweight worldwide. Once considered a problem of affluence, obesity is fast growing in many developing countries also.4 Even in countries like India, which are typically known for high prevalence of under nutrition, a significant proportion of overweight and obese children now coexist with those who are under nourished. ${ }^{5}$ National representative data for childhood obesity in India is unavailable, however available studies of Chennai and Delhi has shown that prevalence of $6.2 \%$ and $7.4 \%$ respectively.[3],[4] $50-80 \%$ of obese children will continue as obese adults ${ }^{5}$ and falls into risk group of Diabetes, Hypertension, Coronary Heart Diseases and many more obesity related diseases. Complications of adult obesity are made worse if the obesity begins in childhood. Obesity is harder to treat in adults than in children ${ }^{6}$ Effective prevention of adult obesity will require the prevention and management of child hood obesity. ${ }^{7}$ WHO has also emphasized on urgent need of understanding the prevalence trend, factors contributing and developing strategies for effective intervention.

MATERIALS AND METHODS: This was a school-based, cross-sectional study.1178 students studying between first and tenth standard of an affluent school (where the annual fees is more than 15000) of Kochi city were selected for the study. The data was, analyzed at Cochin medical college. Standing 
height was measured using a portable stadiometer. The child stood in socks on the flat base of the stadiometer with the back of the head, shoulder blades, buttocks and heels touching the vertical rod, and head in the Frankfurt plane. Gentle traction was applied to the mandibular process and the headboard lowered. The reading was taken to the last completed $\mathrm{mm}$, avoiding parallax, and two such readings were averaged for analysis. Weight was measured using portable weighing scales accurate to $100 \mathrm{~g}$. BMI is used as a screening tool to identify possible weight problems for children. For children and teens, BMI is age-and gender-specific and is often referred to as "BMI-for-age." The CDC and the American Academy of Pediatrics (AAP) recommend the use of BMI to screen for overweight and obesity in children beginning at two years old. However, BMI is not a diagnostic tool.

For children and teens, after BMI is calculated, the BMI number is plotted on the CDC BMI-forage growth charts (for either girls or boys) to obtain a percentile ranking. Percentiles are the most commonly used indicator to assess the size and growth patterns of individual children in the United States. Percentiles are used for children and teens because the amount of body fat differs between boys and girls and body fat also changes with age. The percentile indicates the relative position of the child's BMI number among children of the same sex and age. The International Obesity Task Force references were used to define overweight and obesity in this study. [13]. Children were categorized into two groups namely overweight (85th to less than the 95th percentile) and obese. (Equal to or greater than the 95th percentile).

\section{STATISTICS:}

Chi-square test

Odds ratio $=1.4879368>1$

Odd's ratio indicates that there is strong hazardous association between sex and obesity.

RESULTS: A total of 1178 children in the age group of 6-17 years were analyzed. Out of these 643 subjects were males and 535 subjects were females Table-1. The overall prevalence of overweight was $10.1 \%$ and obesity was $5.6 \%$ [Table 3]. The prevalence of overweight was $11.5 \%$ among boys and $8.41 \%$ among girls; $6.53 \%$ and $4.49 \%$ were obese, respectively. However, according to the Body Mass Index cut off values, 84.29\% \% (993) were normal, 10.1\% (119) were overweight, and $5.6 \%$ (66) were obese.

\begin{tabular}{|c|c|c|c|}
\hline Age & Boys & Girls & Total \\
\hline 6 & 51 & 62 & 113 \\
\hline 7 & 68 & 44 & 112 \\
\hline 8 & 55 & 55 & 110 \\
\hline 9 & 69 & 46 & 115 \\
\hline 10 & 69 & 48 & 117 \\
\hline 11 & 59 & 60 & 119 \\
\hline 12 & 64 & 57 & 121 \\
\hline 13 & 70 & 54 & 124 \\
\hline 14 & 70 & 56 & 126 \\
\hline 15 & 68 & 53 & 121 \\
\hline Total & $\mathbf{6 4 3}$ & $\mathbf{5 3 5}$ & $\mathbf{1 1 7 8}$ \\
\hline Table $1:$ Age
\end{tabular}

Table 1: Age and Sex Distribution of the Study Group 
A total of 1178 children in the age group of 6- 17 years were analyzed. Out of these 643 subjects were males, and 535 subjects were females.

\begin{tabular}{|c|c|c|}
\hline Age in years & Boys & Girls \\
\hline 6 & 18.4142 & 18.8378 \\
\hline 7 & 19.1524 & 19.6779 \\
\hline 8 & 20.0679 & 20.6953 \\
\hline 9 & 21.0889 & 21.8173 \\
\hline 10 & 22.1541 & 22.9826 \\
\hline 11 & 23.2136 & 24.1414 \\
\hline 12 & 24.2299 & 25.2556 \\
\hline 13 & 25.1781 & 26.2988 \\
\hline 14 & 26.0466 & 27.256 \\
\hline 15 & 26.8369 & 28.1237 \\
\hline
\end{tabular}

\section{Table 2: $95^{\text {th }}$ Percentile of BMI for Boys and Girls}

For children and teens, after BMI is calculated, the BMI number is plotted on the CDC BMI-forage growth charts (for either girls or boys) to obtain a percentile ranking.

\begin{tabular}{|c|c|c|c|}
\hline Sex & Obese & Non obese & Total \\
\hline Boys & $42(6.53 \%)$ & $601(93.47 \%)$ & $643(100 \%)$ \\
\hline Girls & $24(4.49 \%)$ & $511(95.51 \%)$ & $535(100 \%)$ \\
\hline Total & $66(5.60 \%)$ & $1112(94.40 \%)$ & $1178(100 \%)$ \\
\hline \multicolumn{4}{|c|}{ Table 3: Prevalence of Obesity by Sex } \\
\hline
\end{tabular}

Statistical Test $(\mathrm{P}=0.1285)$

Epidemiological Test

Odd's ratio indicates that there is strong hazardous association between sex and obesity.

Odds ratio $=1.4879368>1$

\begin{tabular}{|c|c|c|c|}
\hline Age & Obese & Non obese & Total \\
\hline 6 & $4(3.54 \%)$ & $109(96.46 \%)$ & $113(100 \%)$ \\
\hline 7 & $10(8.93 \%)$ & $102(91.07 \%)$ & $112(100 \%)$ \\
\hline 8 & $13(11.82 \%)$ & $97(88.18 \%)$ & $110(100 \%)$ \\
\hline 9 & $12(10.43 \%)$ & $103(89.57 \%)$ & $115(100 \%)$ \\
\hline 10 & $5(4.27 \%)$ & $112(95.73 \%)$ & $117(100 \%)$ \\
\hline 11 & $1(0.84 \%)$ & $118(99.16 \%)$ & $119(100 \%)$ \\
\hline 12 & $3(2.48 \%)$ & $118(97.52 \%)$ & $121(100 \%)$ \\
\hline 13 & $6(4.84 \%)$ & $118(95.16 \%)$ & $124(100 \%)$ \\
\hline 14 & $5(3.97 \%)$ & $121(96.03 \%)$ & $126(100 \%)$ \\
\hline 15 & $7(5.79 \%)$ & $114(94.21 \%)$ & $121(100 \%)$ \\
\hline Total & $66(5.60 \%)$ & $1112(94.4 \%)$ & $1178(100 \%)$ \\
\hline \multicolumn{4}{|c|}{ Table 4: Prevalence of 0besity by Age } \\
\hline
\end{tabular}




\begin{tabular}{|c|c|c|}
\hline Sex & Overweight & Obese \\
\hline Boys & $74(11.50 \%)$ & $42(6.53 \%)$ \\
\hline Girls & $45(8.41 \%)$ & $24(4.49 \%)$ \\
\hline Total & $119(10.10 \%)$ & $66(5.60 \%)$ \\
\hline
\end{tabular}

Table 5: Prevalence of Overweight and Obesity Sex wise

The overall prevalence of overweight among the urban group was found to be $10.1 \%$, and obesity was found to be $5.6 \%$

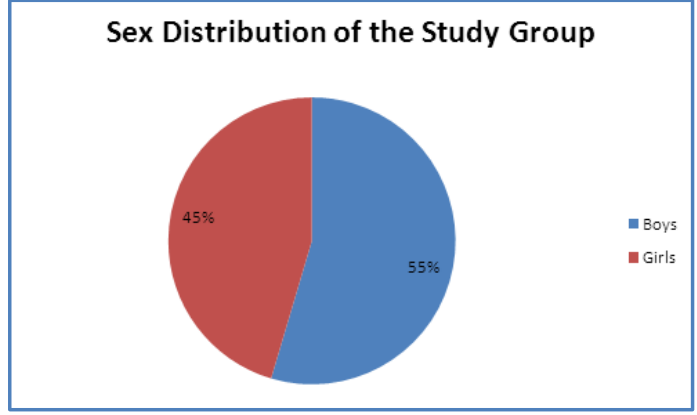

Diagram 1

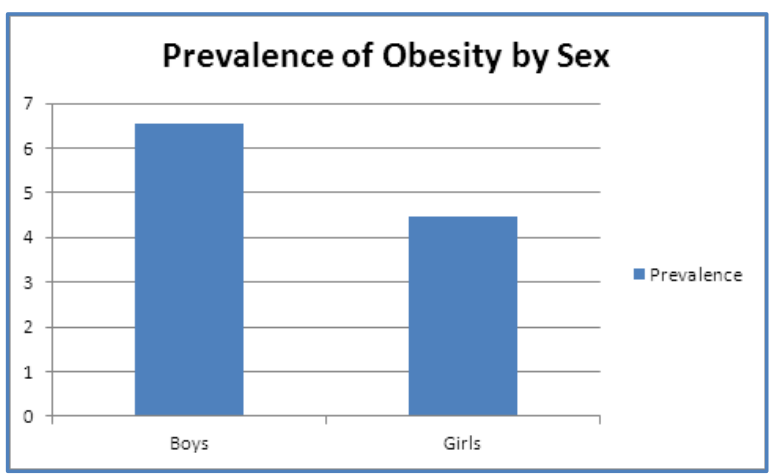

Diagram 3

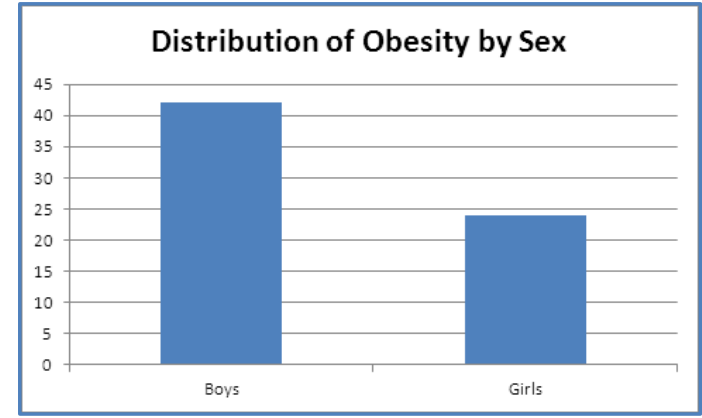

Diagram 2

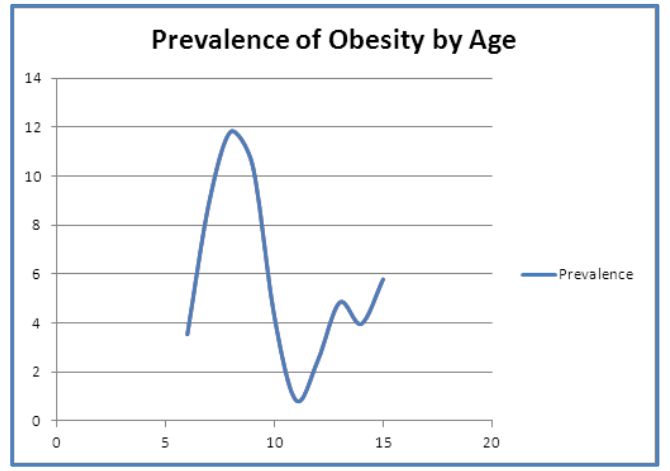

Sex Graph 1

DISCUSSIONS: The overall prevalence of overweight among the urban group was found to be $10.1 \%$, and obesity was found to be $5.6 \%$ \{Table- 3 \} which was consistent with a recent study ${ }^{2}$ However, the National Nutrition Monitoring Bureau surveys in 2002, in rural areas, reported the prevalence of as little as $0.6 \% .^{3}$ A similar study done in Hyderabad showed that the prevalence of overweight was $7.2 \%$ among the 12 to 17 year age group. ${ }^{4}$ Although, some other studies done in India showed a higher prevalence of overweight and obesity. ${ }^{5-8} \mathrm{~A}$ study in Delhi on affluent school children showed the prevalence of obesity to be $7.4 \% .{ }^{9}$ Another study among affluent girls in Delhi reported the prevalence of obesity and overweight to be 5.3 and $15.2 \%$, respectively. ${ }^{10}$ Similar studies had been conducted to assess the prevalence of overweight and obesity in India and the results are comparable to our study, with respect to the prevalence of obesity. ${ }^{11,14} \mathrm{~A}$ study done in USA during 2001-2002 showed the prevalence of overweight and obesity as 31.5 and $16.5 \%$, respectively, for the 6 to 19 
year age group. ${ }^{15}$ The widely differing prevalence of overweight and obesity was due to the definitions used, age group and sex taken for the study, uniformity of selection of the sample, area selected, and the methodology used for the survey. Overweight and obesity were marginally higher in the pubertal age groups of 13 to 15 years, perhaps because of increased adipose tissue and overall body weight in children during puberty. One of the major reasons for childhood obesity was watching television or using computers as shown by another study. ${ }^{4,16}$ A clear socioeconomic gradient in the prevalence of overweight and obesity was observed in this study, which was consistent with other studies. ${ }^{4,5,17}$ The results revealed that regular physical activity was an important factor in reducing the prevalence of overweight and obesity, which was consistent with other studies. ${ }^{4,5}$

\section{REFERENCES:}

1. Subramanya V, JayaShree R, Rafi M. Prevalence of overweight and obesity in affluent adolescent girls in Chennai in 1981 and 1998. Indian Pediatr 2003; 40:332-6.

2. Aggarwal T, Bhatia RC, Singh D, Sobti PC. Prevalence of obesity and overweight in affluent adolescents from Ludhiana, Punjab. Indian Pediatr 2008; 45:500-01.

3. National Nutrition Monitoring Bureau. Diet and nutritional status of rural population national institute of nutrition. Indian Council of Medical Research Hyderabad, India: 2002.

4. Laxmaiah A, Nagalla B, Vijayaraghavan K, Nair M. Factors affecting prevalence of overweight among 12 to 17 year-old urban adolescents in Hyderabad, India. Obesity (Silver Spring) 2007; 15:1384-90.

5. Ramachandran A, Snehalatha C, Vinitha R, Thayyil M, Kumar CK, Sheeba L, et al. Prevalence of overweight in urban Indian adolescent school children. Diabetes Res Clin Pract 2002; 57:18590.

6. Chatterjee P. India sees parallel rise in malnutrition and obesity. Lancet 2002; 360:1948.

7. Kaur S, Kapil U, Singh P. Pattern of chronic diseases amongst adolescent obese children in developing countries. Curr Sci 2005; 88:1052-6.

8. Khadilkar VV, Khadilkar AV. Prevalence of obesity in affluent school boys in Pune. Indian Pediatr 2004; 41:857-8.

9. Kapil U, Singh P, Pathak P, Dwivedi SN, Bhasin S. Prevalence of obesity amongst affluent adolescent school children in Delhi. Indian Pediatr 2002; 39:449-52.

10. Mehta M, Bhasin SK, Agrawal K, Dwivedi S. Obesity amongst affluent adolescent girls. Indian J Pediatr 2007; 74:619-22.

11. Kaneria Y, Singh P, Sharma DC. Prevalence of overweight and obesity in relation to socio economic conditions in two different groups of school age children of Udaipur city (Rajasthan). J Indian Assoc Community Med 2006; 7:133-5.

12. Jelliffee DB. Assessment of nutritional status of the community. Geneva: World Health Organization; 1988.

13. Cole TJ, Bellizzi MC, Flegal KM, Dietz WH. Establishing a standard definition for child overweight and obesity: International survey. BMJ 2000; 320:1-6.

14. Sidhu S, Marwah G, Prabhjot. Prevalence of overweight and obesity among the affluent school children of Amritsar, Punjab. Coll Antropol 2005; 29:53-5.

15. Hedley AA, Ogden CL, Johnson CL, Carroll MD, Curtin LR, Flegal KM. Prevalence of overweight and obesity among US children, adolescents and adults. 1999-2002. JAMA 2004; 291:2847-50. 


\section{ORIGINAL ARTICLE}

16. Eisenmann JC, Bartee RT, Wang MQ. (2002) Physical activity, TV viewing, and weight in US youth: Youth risk behaviour survey. Obestet Res 1999; 10:379-85.

17. Kasmini K. Prevalence of overweight and obesity among school children aged between 7-16 years amongst the 3 major ethnic groups in Kuala Lampur, Malaysia. Asia Pac J Clin Nutr 1997; 6:172-4.

\section{AUTHORS:}

1. Shiji K. Jacob

\section{PARTICULARS OF CONTRIBUTORS:}

1. Associated Professor, Department of Pediatrics, Cochin Medical College, Kochi.

\section{NAME ADDRESS EMAIL ID OF THE} CORRESPONDING AUTHOR:

Dr. Shiji K. Jocob,

Bethel - Kochuvadakethil,

Moolepadam, Kalamassery,

P. 0 - 683104 .

E-mail: shijijacob70@gmail.com

Date of Submission: 30/01/2014.

Date of Peer Review: 31/01/2014.

Date of Acceptance: 10/02/2014.

Date of Publishing: 21/02/2014. 